Aim of the study: PROFIL was a prospective observational study conducted to investigate physicians' evaluation of febrile neutropenia (FN) risk and reasons for giving pegfilgrastim primary prophylaxis (PP) in routine clinical practice in Poland.

Material and methods: Adult cancer patients treated with chemotherapy (CT), assessed by investigators as having high overall FN risk, and who received pegfilgrastim in cycle 1 were enrolled between 03/2009 and 09/2010. Investigators assessed FN risk of the $\mathrm{CT}$ regimen, individual risk factors, and overall FN risk, and were asked to provide the most important reasons for providing pegfilgrastim PP. Investigator-assessed CT FN risk was compared with guideline classification.

Results: Data were analysed from 1006 breast, ovarian, and lung cancer, and non-Hodgkin (NHL) and Hodgkin lymphoma (HL) patients. The most important reasons for using pegfilgrastim PP were high CT FN risk and advanced disease; these were consistent across tumour types and treatment intent. The investigators generally assessed high CT FN risk in agreement with guideline classification. Febrile neutropenia occurred in $4 \%$ of patients, most commonly in $\mathrm{HL}$, NHL, and patients with advanced disease.

Conclusions: High CT FN risk and advanced stage of disease were found to be the most important reasons for providing pegfilgrastim PP by physicians in Poland.

Key words: febrile neutropenia, chemotherapy, pegfilgrastim, GCSF, risk category.

Contemp Oncol (Pozn) 2015; 19 (3): 214-219 DOI: $10.5114 /$ wo.2015.52657

\section{Multicentre, Prospective Observational Study of Pegfilgrastim Primary Prophylaxis in Patients at High Risk of Febrile Neutropenia in Poland: PROFIL Study}

\author{
Wojciech Jurczak ${ }^{1}$, Ewa Kalinka-Warzocha², Ewa Chmielowska ${ }^{3}$, \\ Renata Duchnowska ${ }^{4}$, Elzbieta Wojciechowska-Lampka ${ }^{5}$, \\ Karolina Wieruszewska ${ }^{6}$
}

${ }^{1}$ Department of Hematology, Jagiellonian University, Krakow, Poland ${ }^{2}$ Department of Chemotherapy, Regional Oncology Center, Lodz, Poland ${ }^{3}$ Department of Clinical Oncology, Oncology Centre, Bydgoszcz, UMK, Torun, Poland ${ }^{4}$ Department of Oncology, Military Institute of Medicine, Warsaw, Poland ${ }^{5}$ The Maria Sklodowska-Curie Memorial Cancer Centre and Institute, Warsaw, Poland ${ }^{6}$ Amgen Biotechnologia Sp.z o.o., Warsaw, Poland

\section{Introduction}

Febrile neutropenia (FN) is a serious side effect of myelosuppressive chemotherapy (CT), carrying a high risk of mortality and typically requiring hospitalisation with intensive treatment $[1,2]$. As a consequence of FN, CT is often reduced or delayed $[3,4]$, and reduced relative dose intensity of CT potentially compromises the success of curative treatment $[5,6]$.

Prophylactic use of recombinant human granulocyte-colony stimulating factor (G-CSF) has been shown to reduce the incidence of CT-related FN [7], and guidelines recommend G-CSF primary prophylaxis (PP) in all patients with high ( $\geq 20 \%$ ) overall FN risk [8-10]. High overall FN risk may arise from high-risk CT alone, or from intermediate-risk CT combined with individual risk factors (e.g. age $\geq 65$ years, advanced disease, prior FN) [8-10].

Pegfilgrastim is a once-per-cycle G-CSF registered for prophylaxis of FN in patients receiving myelosuppressive $\mathrm{CT}$ [11]. A range of studies have indicated that PP with pegfilgrastim may provide better protection from FN than other approaches. For example, in a study of 1256 breast cancer patients receiving TAC, FN incidence was significantly lower with pegfilgrastim prophylaxis $(7 \%)$ than with ciprofloxacin $(22 \%)$ or daily G-CSF prophylaxis on days 5-10 (18\%) [12]. Furthermore, meta-analyses of clinical trials comparing pegfilgrastim with standard G-CSF [7, 13], and an integrated analysis comparing pegfilgrastim PP with current medical practice [14], have all shown the incidence of FN to be significantly lower with pegfilgrastim. Studies of clinical practice suggest that daily G-CSFs are often administered later in the CT cycle and for fewer days than recommended, resulting in an increased risk of hospitalisation for neutropaenic complications [15-22]. Current European guidelines advise that pegfilgrastim may avoid the problem of patients receiving suboptimal daily G-CSFs [8].

Except for when the CT regimen alone carries an FN risk $\geq 20 \%$, the decision of whether to use G-CSF prophylaxis is based on the physician's judgement of the combined impact of CT regimen myelotoxicity, individual risk factors, disease characteristics, and treatment intention [8-10]. Current guidelines provide no quantitative weighting of risk factors or simple algorithms for calculating the combined risk. A number of models for predicting FN risk based on individual risk factors are available [23-29]; however, reli- 
able validation with independent data is required before they can be incorporated into guidelines.

The primary objective of the PROFIL study was to assess how physicians reach the decision to use pegfilgrastim for PP of FN in patients receiving anticancer $C T$ in routine clinical practice in Poland, and to determine the most important reasons for their decision.

\section{Material and methods}

\section{Study design}

This was a multicentre, prospective, observational study. According to local law, there was no requirement for ethical approval. Compliance with local and international guidelines was assessed additionally to the study protocol.

The primary outcome was to identify the most important factors contributing to the decision to use pegfilgrastim for PP of FN. Secondary outcomes included the following: the proportion of patients with dose reduction or delay, with administration of IV anti-infectives, who developed severe neutropenia (grade III/IV) or FN, who were hospitalised for FN or infections, or who experienced serious/non-serious adverse drug reactions (ADRs) suspected of being related to pegfilgrastim by the investigators.

\section{Procedure and data collection}

Eligible patients were adults treated with CT for breast, lung, or ovarian cancer, or lymphoma with a high overall risk of FN ( $\geq 20 \%$ ), who received prophylactic pegfilgrastim according to the SMPC [11] in cycle 1 before study enrolment.

Data on patient and treatment characteristics were collected at baseline.

For the first cycle, investigators separately assessed CT FN risk, individual FN risk factors, and overall FN risk according to EORTC guidelines [8], and provided reasons for pegfilgrastim PP (primary outcome).

Individual FN risk factors were selected from the following: age ( $\geq 65$ years); advanced stage disease/metastases; planned antibiotic prophylaxis; previous FN episode; planned use ofG-CSF; femalegender; haemoglobin < $12 \mathrm{~g} / \mathrm{dl}$; cardiovascular disease; kidney disease; elevated liver enzymes; planned high dose intensity ( $\geq 80 \%)$; poor general condition and/or poor nutritional status; $\geq 1$ comorbidity; body surface area $<2 \mathrm{~m}^{2}$; absolute neutrophil count (ANC) $<1.5 \times 10^{9} /$ before treatment; and albumin $\leq 3.5 \mathrm{~g} / \mathrm{dl}$. Factors were selected only if considered important by the investigator in their overall risk assessment (in some cases the risk factor, although present, may not have been selected because it did not contribute to overall FN risk in the judgement of the investigator).

Reasons for pegfilgrastim PP were entered in order of importance into 3 separate fields, (Reasons 1, 2 and 3 ), each with the following options: age $\geq 65$ years; poor ECOG performance status; female gender; tumour type; advanced disease stage; CT regimen; previous FN episode; poor nutrition status; anaemia (haemoglobin < $12 \mathrm{~g} / \mathrm{dl}$ ); or cardiovascular, liver, or kidney disease. One, two, or all three fields could be used.
Data on outcomes (including FN, other neutropenia-related outcomes, and ADRs) were collected from the first CT cycle throughout treatment. Febrile neutropenia was defined as ANC $<0.5 \times 10^{9} /$, or $<1.0 \times 10^{9} /$ l predicted to fall below $0.5 \times 10^{9} / \mathrm{I}$ within 48 hours, with fever $\left(>38.0^{\circ} \mathrm{C}\right.$ sustained for at least 1 hour, or $>38.5^{\circ} \mathrm{C}$ obtained by a single reading) or clinical signs of sepsis. Dose delays and reductions were defined by investigators.

\section{Statistical analyses}

All parameters were evaluated descriptively. Quantitative data were summarised by means, medians, ranges, and standard deviations. Categorical data were summarised by the number and percentage in each category.

In a post-hoc analysis, CT FN risk was classified according to EORTC, local, ASCO and NCCN guidelines, and published literature [8-10] to enable comparison of investigator-assessed CT FN risk with that published in guidelines. A list of regimens and assigned FN risk categories according to published guidelines is given in Supplementary Online Resource 1.

\section{Results}

\section{Patient and treatment characteristics}

Data from 1006 patients enrolled from 55 cancer treatment centres in Poland between 03/2009 and 09/2010 were analysed. In general, the patient population was relatively young with good performance status (Table 1). The most common tumour type was breast (43\%), followed by non-Hodgkin lymphoma (NHL; $26 \%$ ). Overall, $76 \%$ of patients had advanced (stage III/IV) disease, with an even distribution between the two stages. Notably, lung cancer had a different patient distribution, with $81 \%$ having stage IV disease. Most patients with breast cancer, $\mathrm{HL}$, and $\mathrm{NHL}$ received $C T$ with curative intent; most patients with lung and ovarian cancer received $\mathrm{CT}$ with intent to prolong survival.

For each tumour type, most patients received specific CT regimens: breast cancer $-53 \%$ received AT or TAC; ovarian cancer $-62 \%$ received a taxane-platinum combination; lung cancer $-69 \%$ received platinum-based $\mathrm{CT}$; $\mathrm{NHL}-65 \%$ received $\mathrm{CHOP}$ or $\mathrm{CHOP}$-like $\mathrm{CT}$; and $\mathrm{HL}-46 \%$ received ABVD and 19\% received escalated BEACOPP. Overall, 440 patients (44\%) received taxanes as monotherapy or in combination with other $\mathrm{CT}$.

A significant proportion of patients (44\%) received CT with high FN risk, according to guidelines. Ovarian cancer had the highest proportion of patients receiving regimens that were not classified in guidelines (20\%).

\section{Investigator-assessed chemotherapy febrile neutropenia risk}

Most patients received $\mathrm{CT}$ with an FN risk specified in guideline publications [8-10]; however, 119 patients received regimens with no guideline-assigned FN risk (Supplementary Online Resource 1).

Investigators generally assessed high FN risk CT in agreement with central guideline classification (Table 2). 
Table 1. Patient and treatment characteristics

\begin{tabular}{|c|c|c|c|c|c|c|}
\hline & $\begin{array}{c}\text { Breast } \\
n=431\end{array}$ & $\begin{array}{l}\text { Ovarian } \\
n=110\end{array}$ & $\begin{array}{c}\text { Lung } \\
n=108\end{array}$ & $\begin{array}{c}\text { NHL } \\
n=263\end{array}$ & $\begin{array}{c}\mathrm{HL} \\
n=94\end{array}$ & $\begin{array}{c}\text { Total } \\
n=1006\end{array}$ \\
\hline Age, median (range) & $\begin{array}{c}53 \\
(20-86)\end{array}$ & $\begin{array}{c}57 \\
(36-78)\end{array}$ & $\begin{array}{c}60 \\
(21-81)\end{array}$ & $\begin{array}{c}60 \\
(18-86)\end{array}$ & $\begin{array}{c}35 \\
(18-73)\end{array}$ & $\begin{array}{c}55 \\
(18-86)\end{array}$ \\
\hline Female (\%) & 100 & 100 & 39 & 46 & 49 & 74 \\
\hline ECOGa PS 0-1 (\%) & 94 & 95 & 66 & 65 & 81 & 82 \\
\hline \multicolumn{7}{|l|}{ Cancer stage (\%) } \\
\hline 1 & 4 & 13 & 0 & 2 & 3 & 4 \\
\hline$\|$ & 29 & 11 & 1 & 19 & 20 & 21 \\
\hline III & 45 & 41 & 18 & 29 & 40 & 37 \\
\hline IV & 22 & 35 & 81 & 51 & 36 & 39 \\
\hline \multicolumn{7}{|l|}{ Treatment intent (\%) } \\
\hline Cure & 76 & 39 & 6 & 76 & 92 & 66 \\
\hline Prolong life & 20 & 49 & 80 & 22 & 6 & 29 \\
\hline Palliative & 3 & 12 & 14 & 2 & 2 & 5 \\
\hline CT FN Riskb (\%) & & 45 & & & & \\
\hline$<10 \%$ & 5 & 35 & 4 & 0 & 46 & 12 \\
\hline $10-19 \%$ & 26 & 1 & 47 & 48 & 0 & 33 \\
\hline$\geq 20 \%$ & 62 & 20 & 38 & 33 & 47 & 44 \\
\hline Not categorised & 6 & & 11 & 19 & 7 & 12 \\
\hline
\end{tabular}

Table 2. Comparison of investigator CT FN risk assessment with classification according to guidelines

\begin{tabular}{|c|c|c|c|c|c|}
\hline \multirow{2}{*}{$\begin{array}{l}\text { CT FN risk according } \\
\text { to guidelines }\end{array}$} & \multicolumn{5}{|c|}{ Investigators' assessment of CT FN risk } \\
\hline & $\begin{array}{c}\text { Total, } \\
n\end{array}$ & $\begin{array}{c}\geq 20 \% \\
n(\%)\end{array}$ & $\begin{array}{c}10-19 \% \\
n(\%)\end{array}$ & $\begin{array}{l}<10 \% \\
n(\%)\end{array}$ & $\begin{array}{c}\text { Not evaluated } \\
n(\%)\end{array}$ \\
\hline$\geq 20 \%$ & 442 & $360(81)$ & $35(8)$ & $4(1)$ & $43(10)$ \\
\hline $10-19 \%$ & 327 & $199(61)$ & $88(27)$ & $14(4)$ & $26(8)$ \\
\hline$<10 \%$ & 118 & $62(53)$ & $28(24)$ & $7(6)$ & $21(18)$ \\
\hline Not categorised & 119 & $71(60)$ & $33(28)$ & $4(3)$ & $11(9)$ \\
\hline
\end{tabular}

For regimens with medium-to-low FN risk according to guidelines, physicians tended to rate the FN risk as higher than published. In 19\% (82/442) of patients receiving CT with high FN risk according to guidelines, the CT FN risk was either not evaluated or was estimated as lower by investigators (Table 2).

Investigator-assessed overall febrile neutropenia risk

Of 1006 enrolled patients, 905 (90\%) were assessed separately by investigators according to EORTC guidelines: an overall FN risk of $\geq 20 \%$ was confirmed in 797 (79\% overall). For 692 patients (69\% overall), this level of risk was attributed to the $\mathrm{CT}$ regimen alone, irrespective of other risk factors. However, for 105 patients (10\% overall) the investigators judged that a combination of $\mathrm{CT}$ regimen and individual risk factors raised the overall FN risk to $\geq 20 \%$.

Physicians were asked to select risk factors that contributed to their overall FN risk assessment. The most frequent risk factors chosen by investigators were: female gender (61\%); planned CT dose intensity $\geq 80 \%$ (57\%); advanced stage disease/metastases (52\%); and planned antibiotic prophylaxis (36\%). The least frequent risk factors were: albumin $\leq 3.5 \mathrm{~g} / \mathrm{dl}(7 \%)$; ANC $<1.5 \times 10^{9} /$ l before treatment (5\%); planned use of G-CSF (4\%); and kidney disease (3\%).

Planned high dose intensity of CT ( $\geq 80 \%)$ was cited as an individual FN risk factor for $62 \%$ of patients treated with intention to cure but for only $27 \%$ of those receiving palliative treatment.

\section{Investigator-assessed reasons for PP}

The most important reason given by physicians for providing pegfilgrastim PP were planned high-risk CT, selected for $78 \%$ of patients overall and as the most important reason in $72 \%$ or patients. The most frequent second and third most important reasons were advanced disease (28\%) and female gender (17\%), respectively. Reasons were generally consistent across tumour types and treatment intent (Fig. 1). Although there was opportunity to provide up to 
three reasons, only one reason was given for $25 \%$ of patients, and two reasons were given for $50 \%$ of patients.

\section{Incidence and consequences of febrile neutropenia}

Overall, FN incidence was 4.4\% (Table 3). Most FN cases were in $\mathrm{HL}$ and $\mathrm{NHL}$ patients, and FN incidence was highest in patients with advanced disease. Febrile neutropenia occurred in all three treatment-intention categories. Febrile neutropenia incidence was higher in patients where poor general condition and/or poor nutritional status (12.4\%), baseline albumin $\leq 3.5 \mathrm{~g} / \mathrm{dl}(11.0 \%)$, or baseline ANC $<1.5 \times 10^{9} /$ l $(8.7 \%)$ contributed to physician overall FN risk assessment.

Of the 44 patients who experienced $\mathrm{FN}, 75 \%$ required hospitalisation and $50 \%$ experienced FN in CT cycle 1 . Intravenous anti-infectives were provided to 114 patients (11\%) overall and to $27 \%$ of $\mathrm{NHL}$ patients.

\section{Dose reductions/delays}

Dose reductions/delays occurred in 235 patients (23\%) overall (lowest rate [16\%] in breast cancer; highest rate [34\%] in ovarian cancer). The rate in patients receiving palliative treatment was 35\% (vs. 20\% in patients treated with curative intent).

The most common reasons for dose reductions were haematological toxicities other than neutropenia (27\%), non-haematological toxicities (26\%), and poor general condition of the patient (23\%).

Adverse drug reactions

Bone and joint/muscle pain were the most common ADRs (occurring in $57 \%$ and $56 \%$ of patients, respectively). One patient experienced a serious ADR (granulocytopaenia).

\section{Discussion}

The most important reasons for providing pegfilgrastim $\mathrm{PP}$ to reduce $\mathrm{FN}$ incidence in patients receiving anticancer $\mathrm{CT}$ in routine clinical practice in Poland were consistent with the individual risk factors selected by physicians. Physicians considered the FN risk of planned CT as most important, followed by disease stage, and then female gender (probably because of the large proportion of breast cancer patients included).

The results of this study are corroborated by other studies: high FN risk of planned CT was the most common reason reported by physicians for pegfilgrastim use in an interim analysis of the DIEPP observational study [30], and female gender and advanced stage of disease were among the three most common individual FN risk factors considered by physicians in both the DIEPP and an Austrian observational study $[30,31]$. Age $>65$ years was a commonly-selected risk factor in these two observational studies [30, 31], as recommended in current European guidelines [8]; however, this was less applicable to the younger population of the current study. Often, one or two of these reasons alone were sufficient to form a clear decision to provide pegfilgrastim PP. This was especially true in breast cancer and HL, where patients tended to be younger and

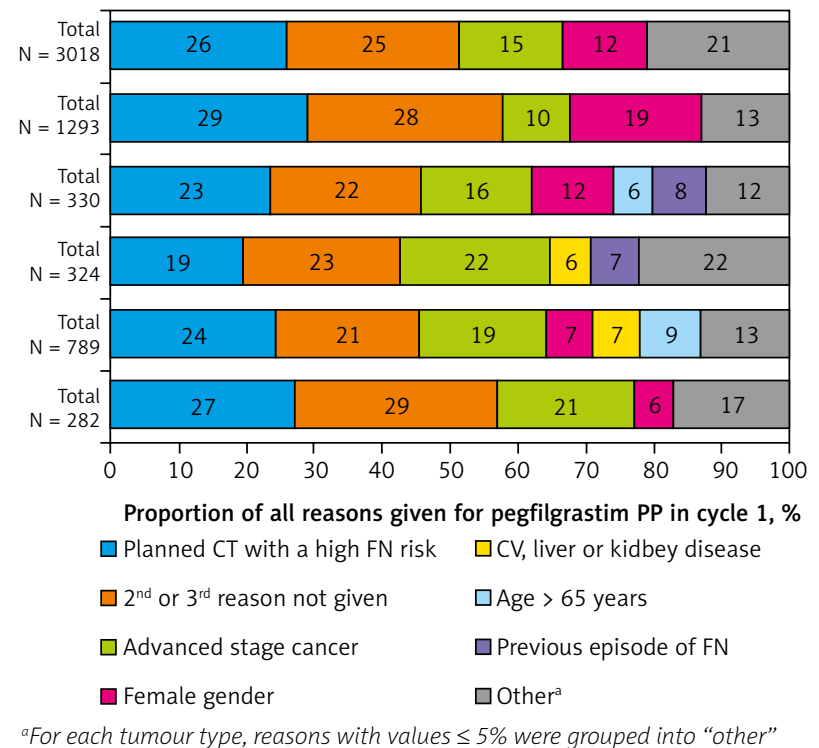

Fig. 1. Distribution of all reasons for pegfilgrastim PP in cycle 1

Table 3. Febrile neutropenia incidence

\begin{tabular}{|c|c|c|}
\hline Variable & $\begin{array}{c}\text { Total } \\
\text { evaluated } \\
n\end{array}$ & $\begin{array}{l}\text { Number who experienced } \\
\geq 1 \mathrm{FN} \text { incident } \\
n(\%[95 \% \mathrm{Cl}])\end{array}$ \\
\hline All & 1006 & $44(4.37$ [3.27-5.82]) \\
\hline $\begin{array}{l}\text { Sex } \\
\text { Female } \\
\text { Male }\end{array}$ & $\begin{array}{l}747 \\
259\end{array}$ & $\begin{array}{c}22(2.95[1.95-4.42]) \\
22(8.49[5.68-12.53])\end{array}$ \\
\hline $\begin{array}{l}\text { Tumour type } \\
\text { Lung } \\
\text { Breast } \\
\text { Ovarian } \\
\mathrm{HL} \\
\mathrm{NHL}\end{array}$ & $\begin{array}{c}108 \\
431 \\
110 \\
94 \\
263\end{array}$ & $\begin{array}{c}0(0[0-3.43]) \\
6(1.39[0.64-3]) \\
0(0[0-3.37]) \\
12(12.77[7.46-21]) \\
26(9.89[6.84-14.09])\end{array}$ \\
\hline $\begin{array}{l}\text { Cancer stage } \\
\text { I } \\
\text { II } \\
\text { III } \\
\text { IV }\end{array}$ & $\begin{array}{c}37 \\
209 \\
372 \\
388\end{array}$ & $\begin{array}{c}0(0[0-9.41]) \\
6(2.87[1.32-6.12]) \\
19(5.12[3.29-7.84]) \\
19(4.90[3.16-7.52])\end{array}$ \\
\hline $\begin{array}{l}\text { Treatment in } \\
\text { Cure } \\
\text { Prolong life } \\
\text { Palliative }\end{array}$ & $\begin{array}{c}664 \\
293 \\
49\end{array}$ & $\begin{array}{c}30(4.52[3.18-6.38]) \\
12(4.1[2.36-7.02]) \\
2(4.08[1.13-13.71])\end{array}$ \\
\hline $\begin{array}{l}\text { Overall FN ris } \\
\geq 20 \% \\
10-19 \% \\
<10 \% \\
\text { Risk not } \\
\text { evaluated }\end{array}$ & $\begin{array}{c}797 \\
101 \\
7 \\
101\end{array}$ & $\begin{array}{c}3 \\
7(4.64[3.39-6.33]) \\
4(3.96[1.55-9.74]) \\
0(0[0-35.43]) \\
3(2.97[1.02-8.37])\end{array}$ \\
\hline
\end{tabular}

more likely to receive CT with curative intent. Perhaps, in this setting, the need to provide the full dose of CT without delay simplifies the decision.

For CT regimens with high FN risk, the investigators of this study were generally in agreement with central guideline classifications, but there was a tendency for investigators to rate the $\mathrm{FN}$ risk of other $\mathrm{CT}$ regimens as higher than published values. Although discrepancies between 
guideline and investigator CT FN risk assessments might simply reflect a lack of awareness of the FN risk associated with some $\mathrm{CT}$ regimens, it is also possible that investigators were reflecting the likely FN incidence in their local patient population, which might differ from the populations enrolled in the original trials used as sources for guideline CT FN risks. Indeed, FN events are often underreported in clinical trials [32], and patient populations in clinical trials are likely to have fewer risk factors than the broader population. For example, current EORTC guidelines cite the FN risk of ABVD as 4\% [8], based on clinical trial data [33], whereas FN rates as high as 11-12\% [34] have been reported in routine clinical practice.

The assignment of CT FN risk was hampered by the lack of reliable data on the $\mathrm{FN}$ risks of many $\mathrm{CT}$ regimens in current use. The FN risk of 29 regimens used in this study, affecting 119 patients (12\%), could not be validated by current guidelines. Additional guidance from retrospective analyses of hospital claims data is limited by the lack of an ICD-9 code for FN, meaning that often only neutropaenia is reported, highlighting the need for continued efforts to provide clarity on the FN risk of CT regimens in current use.

It is also unclear how much individual FN risk factors contribute to overall FN risk. Work is currently underway to validate models for predicting FN risk based on individual risk factors using independent data sources [35], an important requirement if these models are to reliably predict overall FN risk in routine practice. Low albumin and ANC counts at baseline have previously been identified in FN risk models as potential predictors of FN occurrence but are not mentioned in the EORTC risk-assessment algorithm [8, 24, 28]. In this study, both factors contributed infrequently to investigators' overall FN risk assessments, but in patients for whom these factors were chosen FN incidence was higher than in the total population, suggesting that these factors are worthy of further study.

The consequences of FN were significant, with $75 \%$ of patients experiencing $\mathrm{FN}$ in this study requiring hospitalisation. Considering that this patient population was judged to be at $\geq 20 \%$ risk of FN, FN rates were low with pegfilgrastim PP (4\% overall), as reported in other observational studies in which patients at high FN risk received pegfilgrastim [30, 31, 36]. Furthermore, the majority of dose delays that occurred were not neutropaenia related.

Bone pain is common in patients receiving $\mathrm{CT}$, with or without pegfilgrastim support, particularly in those who are young, have breast cancer, and receive taxanes [37, 38]. These characteristics were typical of many of the patients in this study (median age 55 years, $43 \%$ with breast cancer, $44 \%$ received taxanes); it was therefore not surprising that bone pain and joint/muscle pain were the most common ADRs.

The findings of this observational study are limited by being purely descriptive, and, in addition, some features of the population (mostly young age, good performance status, large proportion with breast cancer) might have influenced the results. Comparisons between CT FN risk assessments made by investigators, and those from guidelines, should be taken in the context of the above discussion, relating to the potential influence of different patient characteristics and the setting of community practice versus clinical trials.

In conclusion, high CT FN risk and advanced stage disease were considered the most important reasons for providing pegfilgrastim. Febrile neutropenia incidence was relatively low (4\%) in these high-risk patients with pegfilgrastim PP.

All authors participated in the interpretation of the data, the review and editing of the manuscript, and the final decision to submit the manuscript for publication. WJ, $E K, E C, R D$, and $E W$ performed the clinical research, and $K W$ participated in the design of the study and performed the post-hoc CT FN risk analysis.

Statistical support was provided by Anna Marcisz of 2KMM Sp. z o. o., and medical writing support, in terms of drafting the manuscript and subsequent editorial assistance, was provided by Linda Woodford of Claris2 GmbH; both received funding from Amgen.

The investigators of this study received research support from Amgen. KW is an employee of Amgen, and EKW has received honoraria from Amgen. WJ, EC, RD, and EWL declare no conflicts of interest.

\section{References}

1. Crawford J, Dale DC, Lyman GH. Chemotherapy-induced neutropenia: risks, consequences, and new directions for its management. Cancer 2004; 100: 228-37.

2. Kuderer NM, Dale DC, Crawford J, Cosler LE, Lyman GH. Mortality, morbidity, and cost associated with febrile neutropenia in adult cancer patients. Cancer 2006; 106: 2258-66.

3. Leonard RC, Miles D, Thomas R., Nussey F. Impact of neutropenia on delivering planned adjuvant chemotherapy: UK audit of primary breast cancer patients. Br J Cancer 2003; 89: 2062-8.

4. Pettengell R, Schwenkglenks M, Leonard R, Bosly A, Paridaens R, Constenla M, Szucs TD, Jackisch C. Neutropenia occurrence and predictors of reduced chemotherapy delivery: results from the INC-EU prospective observational European neutropenia study. Support Care Cancer 2008; 16: 1299-309.

5. Wildiers H, Reiser M. Relative dose intensity of chemotherapy and its impact on outcomes in patients with early breast cancer or aggressive lymphoma. Crit Rev Oncol Hematol 2011; 77:221-40

6. Chirivella I, Bermejo B, Insa A, et al. Optimal delivery of anthracycline-based chemotherapy in the adjuvant setting improves outcome of breast cancer patients. Breast Cancer Res Treat 2009; 114: 479-84.

7. Cooper KL, Madan J, Whyte S, Stevenson MD, Akehurst RL. Granulocyte colony-stimulating factors for febrile neutropenia prophylaxis following chemotherapy: systematic review and meta-analysis. BMC Cancer 2011; 11: 404.

8. Aapro MS, Bohlius J, Cameron DA, et al. 2010 update of EORTC guidelines for the use of granulocyte-colony stimulating factor to reduce the incidence of chemotherapy-induced febrile neutropenia in adult patients with lymphoproliferative disorders and solid tumours. Eur J Cancer 2011; 47: 8-32.

9. National Comprehensive Cancer Network. NCCN Clinical Practice Guidelines in Oncology: Myeloid Growth Factors [v.1.2013]. www. nccn.org. Accessed 16 Apr 2013.

10. Smith TJ, Khatcheressian J, Lyman GH, et al. 2006 update of rec ommendations for the use of white blood cell growth factors: an evidence-based clinical practice guideline. J Clin Oncol 2006; 24: 3187-205.

11. European Medicines Agency. Neulasta SmPC. www.ema.europa. eu. Accessed 11 Sep 2013. 
12. von Minckwitz G, Kümmel S, du Bois A, et al.; German Breast Group. Pegfilgrastim +/- ciprofloxacin for primary prophylaxis with TAC (docetaxel/doxorubicin/cyclophosphamide) chemotherapy for breast cancer. Results from the GEPARTRIO study. Ann Oncol 2008; 19, 292-8

13. Pinto L, Liu Z, Doan Q, Bernal M, Dubois R, Lyman G. Comparison of pegfilgrastim with filgrastim on febrile neutropenia, grade IV neutropenia and bone pain: a meta-analysis of randomized controlled trials. Curr Med Res Opin 2007; 23: 2283-95.

14. von Minckwitz G, Schwenkglenks M, Skacel T, Lyman GH, Pousa AL, Bacon P, Easton V, Aapro MS. Febrile neutropenia and related complications in breast cancer patients receiving pegfilgrastim primary prophylaxis versus current practice neutropaenia management: results from an integrated analysis. Eur J Cancer 2009; 45: 608-17.

15. Almenar D, Mayans J, Juan O, et al. Pegfilgrastim and daily granulocyte colony-stimulating factor: patterns of use and neutropenia-related outcomes in cancer patients in Spain - results of the LEARN Study. Eur J Cancer Care (Engl) 2009; 18: 280-6.

16. Almenar Cubells D, Bosch Roig C, Jiménez Orozco E, et al.; LEARN II Study Group. Effectiveness of daily versus non-daily granulocyte colony-stimulating factors in patients with solid tumours undergoing chemotherapy: a multivariate analysis of data from current practice. Eur J Cancer Care (Engl) 2013; 22: 400-12.

17. Morrison VA, Wong M, Hershman D, Campos LT, Ding B, Malin J. Observational study of the prevalence of febrile neutropenia in patients who received filgrastim or pegfilgrastim associated with 3-4 week chemotherapy regimens in community oncology practices. J Manag Care Pharm 2007; 13: 337-48.

18. Naeim A, Henk HJ, Becker L, Chia V, Badre S, Li X, Deeter R. Pegfilgrastim prophylaxis is associated with a lower risk of hospitalization of cancer patients than filgrastim prophylaxis: a retrospective United States claims analysis of granulocyte colony-stimulating factors (G-CSF). BMC Cancer 2013; 13: 11

19. Tan H, Tomic K, Hurley D, Daniel G, Barron R, Malin J. Comparative effectiveness of colony-stimulating factors for febrile neutropenia: a retrospective study. Curr Med Res Opin 2011; 27: 79-86.

20. Weycker D, Hackett J, Edelsberg JS, Oster G, Glass AG. Are shorter courses of filgrastim prophylaxis associated with increased risk of hospitalization? Ann Pharmacother 2006; 40: 402-7.

21. Weycker D, Malin J, Kim J, Barron R, Edelsberg J, Kartashov A, Oster G. Risk of hospitalization for neutropenic complications of chemotherapy in patients with primary solid tumors receiving pegfilgrastim or filgrastim prophylaxis: a retrospective cohort study. Clin Ther 2009; 31: 1069-81.

22. Weycker D, Malin J, Barron R, Edelsberg J, Kartashov A, Oster G. Comparative effectiveness of filgrastim, pegfilgrastim, and sargramostim as prophylaxis against hospitalization for neutropenic complications in patients with cancer receiving chemotherapy. Am J Clin Oncol 2012; 35: 267-74.

23. Hosmer W, Malin J, Wong M. Development and validation of a prediction model for the risk of developing febrile neutropenia in the first cycle of chemotherapy among elderly patients with breast, lung, colorectal, and prostate cancer. Support Care Cancer 2011; 19: 333-41.

24. Lyman GH, Dale DC, Friedberg J, Crawford J, Fisher RI. Incidence and predictors of low chemotherapy dose-intensity in aggressive non-Hodgkin's lymphoma: a nationwide study. J Clin Oncol 2004; 22: 4302-11.

25. Lyman GH, Lyman CH, Agboola O. Risk models for predicting che motherapy-induced neutropenia. Oncologist 2005; 10: 427-37.

26. Lyman GH, Kuderer NM, Crawford J, Wolff DA, Culakova E, Poniewierski MS, Dale DC. Predicting individual risk of neutropenic complications in patients receiving cancer chemotherapy. Cancer 2011; 117: 1917-27.

27. Moreau M, Klastersky J, Schwarzbold A, et al. A general chemotherapy myelotoxicity score to predict febrile neutropenia in hematological malignancies. Ann Oncol 2009; 20: 513-9.

28. Pettengell R, Bosly A, Szucs TD, Jackisch C, Leonard R, Paridaens R, Constenla M, Schwenkglenks M. Multivariate analysis of febrile neutropenia occurrence in patients with non-Hodgkin lymphoma: data from the INC-EU Prospective Observational European Neutropenia Study. Br J Haematol 2009; 144: 677-85.
29. Schwenkglenks M, Pettengell R, Jackisch C, Paridaens R, Constenla M, Bosly A, Szucs TD, Leonard R. Risk factors for chemotherapy-induced neutropenia occurrence in breast cancer patients: data from the INC-EU Prospective Observational European Neutropenia Study. Support Care Cancer 2011; 19: 483-90.

30. Csoszi T, Safanda M, Mazur G, Mihaylov G, Benkovičová J, Tóth E. The neutropenia prophylaxis evaluation program in patients receiving myelosuppressive chemotherapy with moderate or high risk of febrile neutropenia - an interim analysis of the DIEPP study. Ann Oncol 2012; 23 (Suppl 9): abstract 1560P.

31. Fiegl M, Steger GG, Studnicka M, Eisterer W, Jaeger C, Willenbacher W. Pegfilgrastim prophylaxis in patients at different levels of risk for chemotherapy-associated febrile neutropenia: an observational study. Curr Med Res Opin 2013; 29: 505-15.

32. Dale DC, McCarter GC, Crawford J, Lyman GH. Myelotoxicity and dose intensity of chemotherapy: reporting practices from randomized clinical trials. J Natl Compr Canc Netw 2003; 1: 440-54.

33. Silvestri F, Fanin R, Velisig M, Barillari G, Virgolini L, Zaja F, Russo D, Baccarani $M$. The role of granulocyte colony-stimulating factor (filgrastim) in maintaining dose intensity during conventional-dose chemotherapy with ABVD in Hodgkin's disease. Tumori 1994; 80: 453-8.

34. Schwenkglenks M, Pettengell R, Szucs TD, Culakova E, Lyman GH. Hodgkin lymphoma treatment with ABVD in the US and the EU: neutropenia occurrence and impaired chemotherapy delivery. J Hematol Oncol 2010; 3: 27.

35. Schwenkglenks M, Bendall KL, Pfeil AM, Szabo Z, Pettengell R. External validation of a risk model of febrile neutropenia occurrence in patients with non-Hodgkin lymphoma. Leuk Lymphoma 2013; 54: 2426-32.

36. Kurbacher C, Eschenburg H, Steffens CC, et al. Febrile neutropenia (FN) risk assessment and granulocyte colony-stimulating factor (G-CSF) guideline adherence in patients with solid tumours or lymphoma - results from a German prospective multicentre observational study (PROTECT). Onkologie 2012; 35: 73.

37. Gregory SA, Schwartzberg LS, Mo M, Sierra J, Vogel C. Evaluation of reported bone pain in cancer patients receiving chemotherapy in pegfilgrastim clinical trials: a retrospective analysis. Community Oncology 2010; 7: 297-308

\section{Address for correspondence}

\section{Karolina Wieruszewska}

Amgen Biotechnologia Sp. z o.o.

Domaniewska 50

02-762 Warsaw, Poland

e-mail: karolina@amgen.com

Submitted: 8.04.2015

Accepted: $\quad 8.06 .2015$ 